\title{
Safeguarding Human Rights from Problematic Technologies
}

\author{
Lea Shaver*
}

"Water is life. Life without water is not life. One cannot speak of a dignified human existence if one is denied access to water."

High Court Decision (2008), Para. 124

“[T]he right of access to sufficient water ... does not require the state ... to provide every person with sufficient water ... [R]ather it requires the state to take reasonable legislative and other measures progressively to realise the achievement of the right of access to sufficient water, within available resources."

\section{Constitutional Court Decision (2009), Para. 50}

Beginning in 2004, impoverished black residents of Phiri township, in South Africa's Soweto area, began to encounter a previously unknown technology: the prepaid water meter. Phiri residents had previously enjoyed a standard piped water supply billed at a flat monthly rate. The majority of these desperately poor households could not afford to pay their water bills. Because it is illegal under South African law to disconnect water services as a penalty for debt, however, the water supply had long been, in effect, free. The new technology was installed on each home's water line in order to restrict this free water supply. Each household was allotted a monthly ration of free water. Additional amounts could be released only by purchasing tokens to insert into the meter.

This "demand-management" technology was hailed by the City of Johannesburg's water utility as an ideal technical solution to a persistent financial problem. Large amounts of water were being consumed yet never paid for in very poor neighborhoods. The water meters achieved the intended goals of conserving water and exacting greater payment. They also led to intense hardship for desperately poor

* The author assisted the South African legal team representing the Mazibuko applicants during 2006 and 2007 while a Fulbright Scholar at the Centre for Applied Legal Studies at the University of Witwatersrand, Johannesburg. 
residents, who had to redirect already scarce resources or go without water for days or weeks at a time. (As an example of the extreme poverty prevalent in Phiri, one resident, Lindiwe Mazibuko, testified that her household of fourteen subsisted on a combined income of under $\$ 100$ per month. $)^{1}$ The prepaid meters quickly became a detested symbol of material deprivation, political marginalization, and the long shadow of apartheid.

Popular frustration with the prepaid water initiative led to community demonstrations and an organized social movement, led by the populist left-wing Anti-Privatization Forum (APF). Massive resistance initially delayed installation of prepaid meters in Phiri. Johannesburg Water obtained court orders forbidding residents from interfering with the work, and a campaign of arrests and punitive water disconnections followed. Organized resistance then weakened, and installations continued. At this point, human rights lawyers heard about the situation and recommended constitutional litigation. With the support of the APF and a mass meeting of Phiri residents, the lawyers agreed to bring suit on behalf of the residents, challenging the installation of the water meters as unconstitutional.

Throughout the resulting litigation, the Phiri prepaid meter conflict was evaluated primarily in terms of the right to water. This right is explicitly recognized in the South African Constitution. ${ }^{2}$ Mazibuko and Others v. City of Johannesburg and Others led to a victory for the human rights plaintiffs at the trial court. That result was largely upheld at an intermediate appellate level. The rights-favorable outcome was dramatically reversed, however, upon final appeal to the nation's highest court. South Africa's Constitutional Court approached the Mazibuko case through the lens of its increasing skepticism of judicial enforcement of social and economic rights. Emphasizing the difficulties of adjudicating rights subject to progressive realization, the Constitutional Court declined to find a violation of the right to water.

Since that time, however, human rights scholars and United Nations bodies have developed a fuller understanding of another human right implicated by prepaid meters: the right to science. Both the Universal Declaration of Human Rights and the International Covenant on Economic, Social, and Cultural Rights assert that everyone has a right to share in the benefits of scientific progress and its applications. ${ }^{3}$ This has been referred to as "the right to enjoy the benefits of scientific progress" or, even more simply, "the right to science." The right to science entails both a positive right of access to technologies essential for a life with dignity, and a

1 Founding Affidavit, Mazibuko and Others v. City of Johannesburg and Others (06/13865) [2008]

-9 68-73.

2 Constitution of the Republic of South Africa, art. 27(1) ("Everyone has the right to have access to ... sufficient food and water.").

3 Universal Declaration of Human Rights, G.A. Res. 217A, December 10, 1948, art. 27(1) ("Everyone has the right ... to share in scientific advancement and its benefits."); International Covenant on Economic, Social and Cultural Rights, G.A. Res. 2200A (XXI) December 16, 1966 , art. 15(1)(b) ("the right of everyone ... to enjoy the benefits of scientific progress and its applications"). 
negative right to protection from the imposition of technology in ways detrimental to human rights and human dignity.

This chapter revisits the Mazibuko case to consider how the conflict over prepaid meters might be analyzed through the lens of the right to science. I suggest that we should understand the rollout of prepaid water meters as a vast technological experiment that was conducted on vulnerable people, at significant risk to their health and well-being. Characterized in this way, the crucial question becomes whether the experiment was conducted with adequate human rights safeguards. Following widely accepted principles of ethical research, such safeguards should include free and informed consent, careful risk-benefit assessments, and appropriate selection of subjects. This new perspective on the prepaid meter controversy offers several forward-looking contributions:

First, this chapter offers a detailed case study of how a seemingly innocuous or even beneficial technology can operate in a context of unequal power to seriously endanger human rights. Various policy and design decisions made around the prepaid water meter technology created a situation that resulted in serious harm. These decisions were made in the context of a certain technological naiveté, bureaucratic carelessness, and/or corporate disinterest in the human rights of the end users. As this case study reveals, technology is not neutral to social injustice. People who are vulnerable by virtue of poverty, lack of education, or social discrimination are also uniquely vulnerable to the harmful application of new and potentially problematic technologies.

Second, this chapter helps to develop the still sparse legal framework of the right to science and proposes a violations approach to understand state duties regarding the right to science. Specifically, I argue that the right to protection from being subjected to technology in ways detrimental to human rights and dignity is immediately justiciable. The chapter uses the Phiri fact pattern to illustrate how human rights advocates can frame a claim in these terms. I also provide guidance as to how courts can evaluate the merits of such claims and fashion appropriate remedies. Even in jurisdictions where the right to science is not legally recognized, it remains possible and productive to rhetorically frame a problematic application of technology as an illegal experiment. This approach can complement invocation of the rights to health, life, and privacy, or any other right impacted by the particular technology at issue.

Third, and most ambitiously, it is my hope that engineers and others responsible for designing and implementing technical interventions can take lessons to avoid similar errors in the future. The framework of human rights safeguards should inform internal processes and policies around other new and potentially problematic technologies. The principles set forth and illustrated here can be applied by designers, technologists, in-house counsel, corporate social responsibility teams, and user communities to evaluate any proposed technological application or intervention. Building a pragmatic approach to conducting human rights impact assessments as a 
matter of routine is likely to be more impactful, in the end, than any campaign of human rights litigation. This is crucial to advancing the ultimate goal: to protect people from harm by anticipating and avoiding potential human rights missteps.

\section{I “DEMAND MANAGEMENT DEVICES”}

From 1948 to 1991, South Africa practiced an extreme form of racial discrimination known as apartheid. Between 1960 and 1983, millions of nonwhite South Africans were forcibly removed from their homes and resettled in racial enclaves under the Group Areas Act. Black South Africans could not vote and were denied basic civil rights. At one time, it was forbidden to publish newspapers in black languages or to teach black students in any language other than the language of the white Afrikaner minority that controlled the country. Decades of internal resistance and international pressure finally propelled the country to end apartheid in the $1990 s$.

Emerging from its first free election in 1994, the new democracy articulated bold goals for racial and economic inclusion. The new constitution was widely hailed as the most progressive in the world, committing to a long list of human rights. At the same time, South African policy-makers fully embraced capitalist development and modernization. South Africa needed to borrow money and attract foreign investment. This led to strong pressure to privatize public utilities as part of the Washington Consensus list of economic policies then viewed as essential for developing countries. An internal political struggle resulted in a compromise: the country would partially, but not fully, privatize key public services.

The political context of the introduction of prepaid water meters in South Africa has been thoroughly analyzed by Patrick Bond and Jackie Dugard. ${ }^{4}$ In the wake of partial privatization, Johannesburg Water continued to be fully owned by the City of Johannesburg. Its operation, however, was largely contracted out to a French company, Suez. From that point forward, Johannesburg Water increasingly emphasized cost recovery as a fundamental principle, notwithstanding the constitutional commitment to water provision as a basic human right. An important component of this strategy was "water demand management," which focused on reducing the amount of water consumed by households too poor to pay standard fees. One component of demand management involved shifting very poor neighborhoods that had enjoyed piped water on credit to more limited water service.

One way this was accomplished was through the installation of prepaid meters in black areas. These meters did not simply measure the amount of water delivered to

4 P. Bond and J. Dugard, "The Case of Johannesburg Water: What Really Happened at the Prepayment 'Parish Pump'” (2008) 12 Law, Democracy, and Development 1-28; J. Dugard, "Choice from No Choice; Rights for the Left? The State, Law and the Struggle against Prepayment Water Meters in South Africa," in S. Molta and A. G. Nilsen (eds.), Social Movements in the Global South: Dispossession, Development and Resistance (Basingstoke: Palgrave Macmillan, 2011), p. 59. 
homes. Their more significant function was to limit the amount of water delivered. The devices were programmed to let through a set ration of free water each month, a nod to the national and constitutional commitment to water as a human right. To access additional water, however, residents had to purchase tokens in advance. The killer feature of the technology was its ability to ensure stricter water conservation and financial discipline. All this was accomplished while bypassing normal legal procedures for discontinuing water service to a property.

Like any technology, prepaid water meters should not be understood as inherently negative or positive from a human rights standpoint. In theory, interruptive water meters could be deployed in a manner supportive of human rights. The technology undoubtedly made it more cost-effective to provide free water to low-income households. The savings might have been reinvested in expanding access to improved water sources for families with no connection at all. Interruptive water devices could also have been used to create shared access points in water-scarce regions, with water tokens distributed like wartime ration coupons. This point is particularly important to appreciate: the practical impact of a technology depends almost entirely upon the myriad particular decisions made by individuals and organizations implementing the technology in a specific social context.

For example, the human rights impact of prepaid water meters depends significantly on the pricing of additional water supply in relation to the resources of each household. If the household has substantial disposable income and tokens are priced very cheaply, it would be merely inconvenient to maintain a supply of tokens to regularly unlock the water supply. However, if the tokens are quite costly compared to the household's limited resources, then the introduction of a prepaid meter imposes a new financial hardship. And if the household is truly desperately poor, then the monthly free water ration can become an oppressive ceiling rather than a supportive floor. From a human rights perspective, prepaid meters would have been least problematic in wealthier households. In practice, however, demand management devices were never introduced in areas where residents could easily afford to pay their water charges. The bureaucratic imperative that led to the adoption of this technology was to reduce unpaid water consumption by the extremely poor.

Another crucial design choice is what amount of free water to permit before restriction begins. With a very generous free water allowance, the devices might have no impact on existing water consumption patterns. With a moderate allowance, families might find that they had sufficient water for sanitation, bathing, drinking, cooking, and washing, but perhaps not enough to raise a kitchen garden, mop their floors, or allow children to play with water. With a meager allowance, residents might find that they faced frequent interruptions in water service and significant new pressure on household budgets already inadequate to meet basic needs.

In Phiri, the free water allowance proved to be meager. Johannesburg Water allotted each household just 6 kiloliters $(\mathrm{kL})$ of free water per month. This was a 
steep 70 percent reduction from the previous estimated consumption of $20 \mathrm{~kL}$ per household. This should not be understood as an oversight or unintended consequence. Johannesburg Water deployed the devices specifically to dramatically reduce water consumption by nonpaying households. To achieve this goal, bureaucrats logically chose a ration well below current usage. Johannesburg Water defended the $6 \mathrm{~kL}$ figure as designed to provide a household of eight residents with 25 liters (6.6 gallons) of water per person per day. However, the average property in Phiri housed not eight, but sixteen residents. Thus, the free basic water ration actually worked out to a daily allowance of less than 15 liters (4 gallons) per person, on average. This level of water consumption is considered meager even within the setting of a desert refugee camp. Studies have found that limiting consumption to this level significantly increases the risk of disease. ${ }^{5}$ Typical Americans use around 333 liters (88 gallons) of water per person per day for home uses. ${ }^{6}$ Phiri residents were permitted only 5 percent of this amount.

Apart from the central question of whether water policy allocated enough free water to very poor households, the installation of prepaid meters impacted access to water in other ways. As might be expected with any new technology, the devices did not always work. Some households complained that their meters behaved erratically, accepting tokens but failing to release water. The devices also had not been well designed to allow residents to monitor their usage and estimate how long the remaining supply would last. Instead, the water supply would be cut off with very little warning. This could happen in the middle of cooking, or while caring for children, or at night, when it was not safe to leave the home to purchase additional tokens. Thus, water might not be available when urgently needed, even if the household was willing and able to pay. In one particularly tragic incident, two small children died when the monthly water supply ran out while residents were attempting to put out a shanty fire. ${ }^{7}$

Another policy decision surrounding the technology was the degree of information and autonomy provided to residents. Although the water company sought consent from each household prior to installing the prepaid meters, the consent was neither free nor informed. Residents were not given an accurate picture of the risks and benefits of prepaid water devices in advance, and they had no ability to withdraw their consent after experiencing the technology firsthand. Phiri residents who complained about problems after meters were installed were told they could not go back to the old system. Residents who resorted to "self-help" measures by

5 A. Cronin et al., "A Review of Water and Sanitation Provision in Refugee Camps in Association with Selected Health and Nutrition Indicators - The Need for Integrated Service Provision" (2008) 6(1) Journal of Water and Health 1-18 at 2.

6 US Environmental Protection Agency, "Statistics and Facts," www.epa.gov/watersense/statis tics-and-facts.

7 Bond and Dugard, "The Case of Johannesburg Water" 1-28. 
attempting to disable or bypass the water-restriction devices were punished with total disconnection from water service.

Users thus did not get to choose the prepaid meter technology; they were subjected to it. Prepaid water meters were deployed in South Africa to serve the cost-saving and revenue-maximizing goals of the agency that had the power to impose the technology rather than the human needs of the persons subjected to it. The design was optimized to meet the needs of the organization that purchased and implemented the devices, but did not take into account the needs of the people who would be directly affected by the technology. Phiri residents were not in control of the technology and did not have input into its design or implementation. They were not consulted about its parameters or informed of its potential risks. And even after the harmful effects became clear, they did not have the freedom to reject it. Technology became yet another means by which poor, black, politically disempowered South Africans were abused.

\section{THE MAZIBUKO LITIGATION}

Because Phiri residents lacked the power or autonomy to shape decisions around the prepaid meter technology, they were ultimately forced to seek redress in the courts. Human rights lawyers from the Center for Applied Legal Studies at the University of Witwatersrand represented them on a pro bono basis. The case was first heard in the High Court of South Africa, Witwatersrand Division. ${ }^{8}$ The City of Johannesburg initially argued that it had no obligation to provide any amount of free water to the poor, but only a statutory obligation to offer water services for a fee. Justice Tsoka dispensed with that argument swiftly, confirming a constitutional obligation "to ensure that every person has both physical and economic access to water." This interpretation was grounded upon the South African Constitution's explicit recognition of the right to water, read in light of international human rights law. ${ }^{10}$ The High Court upheld the amount of $25 \mathrm{~kL}$ per person per day as a reasonable minimum, but emphasized that the city was "obliged to provide more than the minimum if its residents' needs so demand and they are able, within their available resources, to do so." In light of conditions in the Phiri neighborhood, where

8 Mazibuko and Others v. City of Johannesburg and Others (06/13865) [2008] ZAGPHC 491, April 30, 2008 (High Court).

9 Ibid., 41. Here, Judge Tsoka referred to the International Covenant on Economic, Social, and Cultural Rights' guarantees of the right to an adequate standard of living and the right to health; General Comment No. 15 on the Right to Water, issued in 2002 by the UN Committee on Economic, Social, and Cultural Rights; the UN Convention on the Rights of the Child; the African Convention on the Rights of the Child; and the African Charter on Human and Peoples' Rights. For further background, see I. Winkler, The Human Right to Water: Significance, Legal Status, and Implications for Water Allocation (Oxford: Hart Publishing, 2012).

10 Constitution of the Republic of South Africa, art. 27(1).

11 Mazibuko (High Court), 126. 
households are large, sanitation depends upon an adequate water supply, and the residents are "mainly poor, uneducated, elderly, sickly and ravaged by HIV/AIDS," the court concluded that the $6 \mathrm{~kL}$ free water allowance was insufficient. ${ }^{12}$

Judge Tsoka went further, however, characterizing the water restriction devices as inherently unconstitutional because of the automatic shutoff function. The opinion first reviewed judicial opinions regarding water disconnections in Brazil, Argentina, France, and the United Kingdom. The Brazilian and Argentinian precedents were characterized as holding that a water company may not interrupt the supply of water due to nonpayment, because this would be a violation of human rights. ${ }^{13}$ In France, it was noted, water companies are required to make special arrangements to ensure access to water for poor households, and disconnection for failure to pay requires court authorization. ${ }^{14}$ In the United Kingdom, prepayment meters had been declared illegal under national statutes because they offered no notice or opportunity for a hearing prior to the cutoff of water supply. ${ }^{15}$ Similarly, Judge Tsoka held that the use of automatic shutoff devices violated the South African constitutional right to "lawful, reasonable and procedurally fair administrative action," at least for poor households. ${ }^{16}$ Judge Tsoka further condemned the lower procedural protections given to Phiri's poor black residents as "unreasonable, unfair and inequitable ... [and] discriminatory solely on the basis of colour." ${ }^{" 17}$ As a remedy, the High Court ordered that all Phiri residents should receive a free basic water supply of at least 50 liters per person per day and be able to opt out of prepaid meters. ${ }^{18}$

The City of Johannesburg and Johannesburg Water appealed the decision. The Appellate Court also found in favor of the Phiri residents. Its opinion upheld the lower court's determination that the restrictive meters were unauthorized by law, and set the standard for constitutionally adequate water provision only slightly lower, at 42 liters per person per day. At this point, the City of Johannesburg and Johannesburg Water accepted their loss and did not initiate a further appeal. But the applicants themselves decided to push forward. Despite having obtained most of what they sought, including recovery of attorney fees, they pushed forward in hopes that the Constitutional Court would reinstate the High Court's 50 liter per person per day benchmark and establish an even stronger precedent.

What happened next was a stunningly disappointing result for the Mazibuko plaintiffs. To everyone's surprise, the Constitutional Court reversed every aspect of the prior decisions. Instead, the Constitutional Court used the Mazibuko case as an

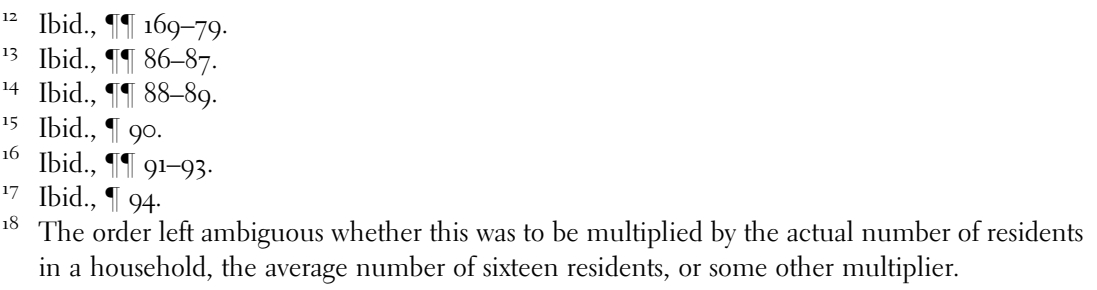


opportunity advance a more conservative vision of "the role of courts in determining the content of social and economic rights." 19 While recognizing the constitutional right to water, the opinion refused to assign any real content to that right. It firmly rejected the notion of setting any quantitative threshold for a constitutionally adequate water supply. ${ }^{20}$ Contrary to the lower courts' reasoning, the Constitutional Court sided with Johannesburg in insisting that the right to water "does not confer a right to claim 'sufficient water' from the state immediately." 21 Rather, it "requires the state to take reasonable legislative and other measures progressively to realise the achievement of the right of access to sufficient water, within available resources." ${ }^{22}$ In judging the city's water policies as lawful and reasonable, the court went out of its way to give the state the benefit of every doubt. The opinion repeatedly emphasized that judicial review in the area of social and economic rights should be very deferential to the democratically accountable branches of government. ${ }^{23}$ Rather than strictly scrutinizing the state's actions, as the High Court and appellate judges had done, the Constitutional Court looked only for a rational basis.

Indeed, the opinion strongly suggests that the sole function of courts with respect to social and economic rights should be to provide a venue where citizens can require government agencies to publicly explain the reasons behind their policies. ${ }^{24}$ This spotlight effect can pressure the government to revise its policies, as happened in this case, with the water agency making several concessions as the case wound its way through the courts. The opinion concluded optimistically:

This case illustrates how litigation concerning social and economic rights can exact a detailed accounting from government and, in doing so, impact beneficially on the policy-making process... Having to explain why the Free Water Policy was reasonable shone a bright, cold light on the policy that undoubtedly revealed flaws. The continual revision of the policy in the ensuing years has improved the policy in a manner entirely consistent with progressive realization. ${ }^{25}$

The opinion's frequent explicit references to "social and economic rights" make clear that this deferential approach to judicial review is reserved specifically for socioeconomic rights. Thus the secret to gaining stronger judicial protection against the use of technology to the detriment of human rights - at least in South Africa, and likely elsewhere as well - is to position it within more familiar frames of traditional civil rights protections against government abuses. The right to science can point the way to such an approach.

19 Mazibuko and Others v. City of Johannesburg and Others [CCT 39-09 2009] ZACC 28, October 8, 2009, ๆ 45-46 (Constitutional Court).

20 Ibid., 9 ฯ $56-57$.

${ }^{21}$ Ibid., 957.

22 Ibid.

23 Ibid., 9 ฯ 59-168.

24 Ibid., $\uparrow \uparrow 160-65$.

25 Constitutional Court, Mazibuko, $\uparrow 153$. 


\section{THE RIGHT TO SCIENCE}

When the Mazibuko case was being litigated in 2007-09, the conceptual foundation for the right to water had only recently been laid. At that time, "the right to science" was not yet even a term in human rights discourse. It was thus not possible for the Mazibuko lawyers to consider framing their case in terms of the right to science, in addition to the right to water. Since that time, however, the right to science has been the subject of significant normative development by scholars and within the United Nations system. ${ }^{26}$

The right to science offers two ways of framing the problems posed by prepaid meters. One is to focus on the aspect of the right to science that calls for expanding access to technology, particularly to what the Special Rapporteur has described as "technologies essential for a life with dignity." 27 Modern indoor plumbing, which permits washing, bathing, cooking, and sanitation, has a strong claim to be considered an essential technology. In this way, the right to science might provide a hook for constitutional litigation in the same way that the right to water did. This view, however, also lends itself to similar weaknesses. This aspect of the right to science is a positive rights claim, subject to the logic of progressive realization. Many courts are hesitant to impose minimum core standards for essential services. Yet without judicially enforced minimums, it often seems impossible to make out a clear violation.

There is a second and, in my view, more interesting way of approaching the right to science as it relates to prepaid meters: to focus on the aspect of the right to science that calls for states "to prevent and preclude the utilization of scientific and technological achievements to the detriment of human rights and fundamental freedoms and the dignity of the human person." ${ }^{\prime 2}$ This approach is based on the notion that

${ }^{26}$ In July 2009, experts convened by UNESCO produced the Venice Statement on the Right to Enjoy the Benefits of Scientific Progress and Its Applications. In 2012, the UN Special Rapporteur in the field of cultural rights, Farida Shaheed, issued a report to the Human Rights Council that endorsed the view of recent scholarship conceiving of "the right to science" as a commitment to treating knowledge and technology as global public goods that must be made widely available. Report of the Special Rapporteur in the Field of Cultural Rights, Farida Shaheed, U.N. Doc. A/HRC/20/26 (May 14, 2012) ("Shaheed Report") (citing L. Shaver, "The Right to Science and Culture" (2010) Wisconsin Law Review 121-85). In 2013, the UN Office of the High Commissioner on Human Rights hosted a highly generative academic seminar on this subject, convened at the UN headquarters in Geneva. Report on the Seminar on the Right to Enjoy the Benefits of Scientific Progress and Its Applications, U.N. Doc. A/HRC/26/19 (April 1, 2014). Another seminar was organized by Prof. Samantha Besson at the University of Freibourg, resulting in a special edition of the European Journal of Human Rights ([2015] European Journal of Human Rights, Special Issue, 403-580). The UN Committee on Economic, Social, and Cultural Rights has also taken early steps to develop a General Comment on the right to science.

27 Shaheed Report, $\uparrow$ 29, 74.

${ }_{28}$ See, e.g., The Declaration on the Use of Scientific and Technological Progress in the Interests of Peace and for the Benefit of Mankind, G.A. Res. 3384 (XXX) (November 10, 1975) ("All States 
technologies are not inherently beneficial or harmful. Problems arise only when technologies are deployed in ways that are detrimental to human rights. Certain categories of technology are more likely to be problematic, however, an idea I will return to later in this chapter.

The right to science offers a framework for anticipating and responding to potential problems through human rights safeguards. This way of framing the legal challenge to demand management devices will refocus attention away from the question of how much water is sufficient - with all the attendant complexity, difficulty, and resistance to defining a quantitative minimum core to be enforced by courts - and instead toward recognition of the coercive application of the restrictive technology as the fundamental harm to be prevented. This way of looking at the right to science presents a classic negative rights claim, a right to freedom from harmful state action. Viewed from this perspective, Phiri residents suffered from a violation of their right not to be subjected to technology in a way that was harmful to their human rights and human dignity.

One way to understand the rollout of prepaid water meters in Phiri is as a massive technological experiment, conducted upon thousands of vulnerable people. Indeed, officials at Johannesburg Water understood the Phiri effort as an experiment. The stated intent was to pilot an unproven technical solution, in order to decide whether to roll it out more broadly. The Phiri prepaid water experiment was problematic for a number of reasons. It involved an unproven technology designed to restrict a substance vital to human life. It was conducted on a very large group of people who were particularly vulnerable by reason of their extreme poverty, including children, pregnant women, elderly people, and people suffering from HIV/AIDS, tuberculosis, and malaria. Subjects were coerced into participating and had no freedom to withdraw from the experiment once it started - in violation of the human rights principle that groups nonconsensual scientific experimentation with torture. ${ }^{29}$ Fewer than twenty-five years after the end of apartheid, only black South Africans

shall take appropriate measures to prevent the use of scientific and technological developments ... to limit or interfere with the enjoyment of human rights and fundamental freedoms... All States shall take effective measures, including legislative measures, to prevent and preclude the utilization of scientific and technological achievements to the detriment of human rights and fundamental freedoms and the dignity of the human person."). That Declaration also mentioned, while giving lesser emphasis to, positive aspects of the right to science, e.g., "all states shall take measures to ensure that scientific and technological achievements satisfy the material and spiritual needs for all sectors of the population"; "[a]ll States shall co-operate in the establishment, strengthening and development of the scientific and technological capacity of developing countries"; and "the state shall take measures to extend the benefits of science and technology to all strata of the population." Ibid., ฯ 3, 5, 6.

29 International Covenant on Civil and Political Rights, G.A. Res. 2200A (XXI), Mar. 23, 1976, art. 7 ("No one shall be subjected to torture or to cruel, inhuman or degrading treatment or punishment. In particular, no one shall be subjected without his free consent to medical or scientific experimentation.") 
were selected for participation. Had university researchers proposed to run such an experiment, they would never have received ethical approval.

\section{HUMAN RIGHTS SAFEGUARDS}

After World War II, Nazi scientists were tried for war crimes for failing to follow internationally accepted ethical standards. The Nuremberg Code, the first international attempt to articulate these standards, remains a foundational document in scientific ethics. The World Medical Association's 1964 Declaration of Helsinki similarly articulates basic standards for human subjects research and is regularly updated. While both of these documents are specifically directed to medical research, the 1978 Belmont Report is framed more broadly. ${ }^{30}$ Its intent was to elaborate "broader ethical principles [to] provide a basis on which specific rules may be formulated, criticized, and interpreted." ${ }^{11}$ The Belmont principles continue to serve as touchstones for research ethics internationally, most significantly in the Universal Declaration on Bioethics and Human Rights. ${ }^{32}$ The high level of generality of these principles makes them particularly useful for thinking about human rights obligations related to the application of new technologies.

\section{A The Threshold Question: When Is Human Rights Scrutiny Required?}

This first step in the Belmont Report was to establish threshold criteria for when special ethical review is required. Similarly, companies, administrative agencies, and courts need criteria to determine when the implementation of a new technology should require special human rights scrutiny.

The Belmont Report distinguished, on the one hand, traditional medical or behavioral "interventions that are designed solely to enhance the well-being of an individual patient or client and that have a reasonable expectation of success." 33 Similarly, a proven technology that is designed primarily to enhance the well-being of the end user should trigger no special human rights scrutiny. Examples include extending traditional water service to new homes, upgrading old or leaking pipes with newer ones, or providing users with a text-messaging hotline to report water problems.

$3^{\circ}$ National Commission for the Protection of Human Subjects of Biomedical and Behavioral Research, The Belmont Report: Ethical Principles and Guidelines for the Protection of Human Subjects of Research (Washington, DC: US Government Printing Office, 1978).

${ }^{31}$ Ibid., p. 1.

$3^{2}$ UNESCO, Universal Declaration on Bioethics and Human Rights, October 19, 2005; see also M. Kruger et al., Research Ethics in Africa: A Resource for Research Ethics Committees (Stellenbosch: Sun Press, 2014) (discussing the Belmont principles as "foundational" and citing the Belmont Report repeatedly).

33 National Commission, The Belmont Report, p. 2. 
In contrast, the Belmont Report cautions that "radically new procedures ... should ... be made the object of formal research at an early stage in order to determine whether they are safe and effective." 34 Prepaid water meters offer an ideal example of a radically new technology that requires safety and efficacy study. The technology had not previously been used in South Africa and had very limited application anywhere in the world. The prepaid meters also operated in a radically new way. Globally, the standard approach to water delivery has always been to provide a secure and consistent source of water controlled by the end user. Traditional water meters measure usage for billing purposes, but do not interrupt the supply against the user's wishes. The prepaid meters, in contrast, dispensed a limited water supply determined by someone other than the user, and required payment in advance for additional amounts, through a brand-new token system.

Moreover, the interruptive meter technology was not designed and selected "solely to enhance the well-being" of the user. ${ }^{35}$ Instead, this technology was selected and designed to advance larger demand-management and cost-recovery goals of Johannesburg Water. This criterion is important, because it helps to determine whether a conflict of interest exists between the person recommending the intervention and the person who will bear the risks. Where such a conflict of interest or tension exists, external review and accountability are recognized as being particularly important. Here, a strong tension existed between the goals of the technology planners and the well-being of individuals who were subjected to the technology. This conflict of interest heightens the risk of harm and therefore the need for human rights safeguards.

A third consideration should be the degree of freedom that individuals have to opt out of using the technology. When people are free to adopt or reject a particular technology, the option to "exit" serves as an important safeguard. When a technology is revealed to be harmful, individuals can often protect themselves by discontinuing its use. If an experimental drug makes a person sick, he or she can stop taking it. If a restrictive water meter is cutting off the water needed to cook, an individual should be able to bypass it. The exit option incentivizes companies to offer well-designed technologies with adequate support, so that consumers do not abandon their products. In a context where individuals are not free to reject a technology, however, these important safeguards are destroyed. Where a government mandates a technology that individuals experience as harmful to their health, liberty, privacy, or other interests, the need for human rights safeguards is paramount.

Finally, technologies that are intentionally designed, in the normal situation of use, to limit human rights call for special scrutiny. Most technologies will not trigger this concern. Seatbelts, credit card security chips, vaccinations, and Internet

35 Ibid., p. 2. 
protocols are all examples of technology that is designed to enhance the user's welfare. Government mandates to use these technologies would not typically be concerning in the ordinary case. In contrast, technologies that are designed to limit privacy, freedom of expression, or access to basic services deserve greater scrutiny. Such technologies would include surveillance technology and water-restriction devices. Dual-use technologies, or technologies that are designed in ways that enable both rights-restricting and rights-enhancing activity, also warrant enhanced scrutiny. Similarly, technologies that automate processes previously subject to the due process of law also deserve special scrutiny.

Prepaid water meters raised all four of these red flags. They were radically new and designed for a purpose other than the user's well-being. People had little to no freedom to opt out of using them. They restricted access to a substance essential for human life. They bypassed existing legal processes by interrupting water access without the required court order. Following the logic of the Belmont principles, these characteristics should have triggered formal research to evaluate their safety and effectiveness. Arguably, the pilot application of the prepaid meter technology in Phiri was this required research. The problem, therefore, was not the complete lack of research, but rather the haphazard and unethical way in which the pilot was designed and carried out.

This can be seen by proceeding to examine the three principles that the Belmont Report lays out to guide ethical research: respect for persons, beneficence, and justice. First, "respect for persons demands that subjects enter into the research voluntarily and with adequate information." ${ }^{36}$ Second, beneficence requires researchers to put the best interests of the research subjects front and center in order to do no harm, or at least to minimize possible harms while maximizing benefits. ${ }^{37}$ Finally, justice requires that persons submitting to the risks of scientific research should benefit from the fruits of that research, and that vulnerable people should not be inappropriately targeted as experimental subjects.

In other words, the Belmont principles establish requirements related to "informed consent, risk/benefit assessment, and the selection of subjects for research." $3^{8}$ The Phiri pilot had significant flaws with respect to each of these criteria. Consent was neither informed nor free, appropriate efforts were not taken to minimize risks, and the selection of subjects was discriminatory.

\section{B Respect for Persons: Ensuring Free and Informed Consent}

The first essential human rights safeguard for experimental technologies is insistence upon free and informed consent. The Belmont Report states, for example, that

$\begin{array}{ll}3^{6} & \text { Ibid., p. } 6 . \\ 37 & \text { Ibid. } \\ 3^{8} & \text { Ibid., p. } 10 .\end{array}$ 
"[r]espect for persons requires that subjects, to the degree that they are capable, be given the opportunity to choose what shall or shall not happen to them. This opportunity is provided when adequate standards for informed consent are satisfied." 39 The Universal Declaration on Bioethics provides: "The autonomy of persons to make decisions, while taking responsibility for those decisions and respecting the autonomy of others, is to be respected. For persons who are not capable of exercising autonomy, special measures are to be taken to protect their rights and interests." 40 According to the Belmont Report, informed consent requires that "the subjects should understand clearly the range of risk and the voluntary nature of participation." ${ }^{11}$ Individuals must be adequately informed of the risks presented by the technology before making a free choice whether to participate or not. "Consent may be withdrawn by the person concerned at any time and for any reason without any disadvantage or prejudice." ${ }^{22}$ Experimentation in a context where consent may be unduly influenced by power dynamics, such as research on prisoners, is highly suspect. ${ }^{43}$ Financial compensation may be offered for research participation, but care must be taken that such incentives do not corrupt freedom of choice, particularly with poor populations.

The consent process followed by Johannesburg Water was egregiously deficient by these standards. Johannesburg Water sent facilitators through the Phiri neighborhood with instructions to obtain signed consent forms from every property owner. Most of the property owners lacked the education to read the consent form, creating the distinct risk that facilitators would mislead them about the nature of the intervention in order to obtain their signatures. Respect for autonomy was so low, water meters were installed even despite some residents' explicit refusal. For example, the lead plaintiff in Mazibuko testified that the facilitator seeking her signature deceived her, stating that the repairs were necessary to replace old and rusty pipes and making no mention of a prepaid meter. Having heard about prepaid meter installations elsewhere, however, she cautiously refused to sign the paper and verbally refused a meter. Notwithstanding her refusal, Johannesburg Water installed a prepaid meter at her property the following day. ${ }^{44}$

Indeed, the vast majority of persons subjected to the Phiri prepaid meter experiment were never even asked for consent. A property owner's signature was deemed sufficient for all residents of the property, whether adults or children, and even for unrelated members of separate households renting backyard shacks. Compounding this problem, the property owner was offered a significant financial benefit in

39 Ibid.

$4^{\circ}$ Universal Declaration on Bioethics, art. 5.

${ }^{41}$ National Commission, Belmont Report, p. 11; see also Universal Declaration on Bioethics, art. 6 .

$4^{2}$ Universal Declaration on Bioethics, art. 6.

43 National Commission, The Belmont Report, p. 6.

44 Founding Affidavit, Mazibuko, 9 79-92. 
exchange for subjecting other residents to the study. Johannesburg Water promised to erase years of past water debts in exchange for formally consenting to the installation of a prepaid meter.

To the extent that consent was sought, it was obtained under duress. Residents were advised that if they did not consent to the installation, their water supply would be completely disconnected. This threat was actually carried out when property owners did not sign the consent form. The lead plaintiff testified that after Johannesburg Water installed a prepaid meter on her property against her wishes, it disconnected her water supply. For several months, she walked 12 kilometers per day to transport water in a wheelbarrow for her household. Eventually, she broke down and "consented" to use a prepaid meter. ${ }^{45}$

An additional fundamental requirement of free and informed consent is that participants have the opportunity to exit at any time. This was not assured in Phiri. Property owners were asked to consent to the installation of an unfamiliar technology. Once they had the opportunity to become familiar with the technology and its limitations and risks, however, there was no procedure by which they could revoke consent and have the device removed.

Finally, no effort was made to inform residents of the risks entailed by water restriction devices, despite their significance. Water authorities knew that the system would force households to dramatically reduce their water consumption. They also knew that the free allowance would be inadequate for even the most basic needs of larger households. Yet this information was not shared with residents, who had no ability to predict how far the free water supply would go in their household or how much they might have to spend on tokens. Some households lost renters who were contributing desperately needed income because the water supply had been downgraded. Other households watched their gardens, which were supplying muchneeded fresh foods, wither and die. Most households had to divert funds from other essential spending in order to meet new water expenses. Households that could not do this would be entirely without water for days or weeks, until the next month's supply began.

In sum, the Phiri prepaid water experiment is a case study in how not to practice informed consent. Gestures were made toward the need for consent, but only to the limited extent that was convenient for Johannesburg Water. There was never any actual respect for the individual's right to refuse. These deficiencies reflect the extremely lopsided power dynamic at play in this particular technological experiment. Johannesburg Water understood itself as entitled to install its technology whether the individuals who were subjected to it wished it or not. Residents' preferences were quite literally deemed to be irrelevant by actors who presumed to make these decisions in their best interest. Judge Tsoka, who had grown up as a black man under apartheid, reacted strongly to the patronizing racism he perceived

45 Ibid., 994. 
in this wholesale denial of options: "That patronization sustained apartheid: its foundational basis was discrimination based on colour and decisions taken on behalf of the majority of the people of the country as 'big brother felt it was good for them'." 46

\section{Beneficence: Maximizing Benefit and Minimizing Harm}

The second principle outlined in the Belmont Report is beneficence. The ordinary meaning of this term is the quality of doing something for the benefit of others. In the context of research ethics, it means that designers of experiments should concern themselves with the welfare of research participants by taking steps to minimize the risks and maximize the benefits to them. The Hippocratic principle "do no harm" is cited as an ideal to be approached. ${ }^{47}$ "In applying and advancing scientific knowledge, medical practice and associated technologies, direct and indirect benefits to patients, research participants and other affected individuals should be maximized and any possible harm to such individuals should be minimized." ${ }^{8}$

It is entirely possible that Johannesburg Water officials believed they were acting in the best interests of the Phiri residents. It is always easy for planners to overestimate the reliability and user-friendliness of a new and untried technology. It is also clear that Johannesburg Water officials believed that substantial water was being wasted due to residents' failure to value what they did not pay for. From their comfortable middle-class perspective, it may have been difficult to imagine that Phiri residents could not afford to pay such tiny charges.

What is clear from the Belmont Report, however, is that good intentions are not enough. Careful and independent scrutiny adds needed accountability to the riskbenefit calculation. "[T]here should first be a determination of the validity of the presuppositions of the research; then the nature, probability and magnitude of risk should be distinguished with as much clarity as possible." 49 A key goal of this process is not merely to prevent unethical experiments from occurring, but also to inform the design of the research in order to minimize the potential for harm and maximize the benefits for those involved.

In this case, a more gradual, careful rollout should have preceded a neighborhood-wide implementation. Water officials should have identified, at the outset, that the technology they sought to implement needed to be field-tested to

${ }^{4}$ Mazibuko (High Court), 153. The white author of the Constitutional Court opinion likely reminded Judge Tsoka of precisely this patronization in concluding that the policy was not "unfairly discriminatory" because the discriminatory impact upon black households could not be judged as harmful, given that Phiri's indigent consumers were, if anything, better off avoiding the "worrying measures" of debt accumulation and collection. Mazibuko (Constitutional Court), 19 148-57.

47 National Commission, Belmont Report, p. 7.

$4^{8}$ Universal Declaration on Bioethics, art. 4.

49 National Commission, Belmont Report, p. 17. 
ensure its safety in the context of acute poverty. They might have first tried the technology in their own offices or homes, to become familiar with its limitations and potential risks (such as device malfunction). The experimental design should also have been informed by research studying current water use patterns in the community. The trial should have started with a restriction at $30 \mathrm{~kL}$ and worked gradually downward toward the target of $6 \mathrm{~kL}$, watching for problems along the way. Each home should have been provided with an emergency water supply in case of device failure. Study participants might have been given cell phones so that they could easily report any urgent problems they experienced. Early participants should have been provided with a supply of tokens, so they would not have to use scarce resources in order to participate in the study.

Another critical safeguard is the participants' ability to end their participation in the experiment, which is relevant to both freedom of consent and minimization of harm. Johannesburg Water should have designed pipes to permit either prepaid or conventional service, at the option of the consumer. This would have secured the exit option and the ability to quickly respond to problems. Had this level of care been put into the Phiri experiment, well-meaning persons at Johannesburg Water and the City of Johannesburg would have been better able to anticipate and manage the risks created by prepaid meters.

\section{Justice: Selection of Experimental Subjects}

The third and final Belmont principle is justice. "The principle of justice gives rise to moral requirements that there be fair procedures and outcomes in the selection of research subjects." ${ }^{\circ}$ The risks of experimentation should not be placed disproportionately upon stigmatized or disadvantaged persons, nor upon persons who already bear great burdens. Where an experiment is conducted on a population of vulnerable persons - such as children, racial or linguistic minorities, or the very poor careful scrutiny is required to ensure that they are not involved solely because they are easier to manipulate. ${ }^{5^{1}}$ The potential benefits to society cannot be used to justify the risks to individuals directly involved. "In applying and advancing scientific knowledge, medical practice and associated technologies, human vulnerability should be taken into account. Individuals and groups of special vulnerability should be protected and the personal integrity of such individuals respected." ${ }^{2}$

Phiri was a community of families already facing massive burdens of poverty, unemployment, and extremely poor health. They should not have been also asked to face the burden of piloting a new and risky technology. The principle of justice would have been advanced by initially testing the technology in middle-class

$5 \circ$ Ibid., p. 18.

51 Ibid.

52 Universal Declaration on Bioethics, art. 8. 
neighborhoods with high levels of education and English fluency. Those users would have been in a better position to cope with and report problems. Eventually, the technology would also need to be tested for safety in the specific social context of poverty, where it was intended to be used. At this stage, the study should not have been designed to involve more people than was necessary. Families with pregnant women, young children, and significant health problems should not have been included in the first wave of experimentation with the devices.

More broadly, we should also ask whether the principle of justice was honored not just in how the technology was field-tested, but also in the plan for its normal use. In litigation, the City of Johannesburg emphasized the public necessity of water conservation. Was it just for the burden of water conservation to be placed upon the extremely poor? If coercive measures were truly necessary to limit water usage, surely they were all the more necessary in affluent homes with much higher water usage per capita. Perhaps policy-makers chose to place this burden upon the poor and socially marginalized residents of Phiri because they were less likely to effectively complain and resist. Or perhaps the need for water conservation was a pretense all along, and the real need was simply to increase monetary recovery. The principle of justice would urge this to be accomplished by charging higher rates in affluent neighborhoods rather than squeezing additional payments from the very poor.

\section{CONCLUSION}

The Mazibuko water dispute highlights the harm that even innocent-seeming technologies can do in the context of a power disparity between designers and users. From beginning to end, this problematic technology was controlled by a powerful institution that designed and implemented it to serve its own purposes, with little regard for the wishes of the vulnerable people subjected to it. The result was a series of decisions about implementation that resulted in serious harm to human dignity, health, and life.

Despite the country's having one of the most rights-protective constitutions in the world, South Africa's Constitutional Court felt unable to remedy this harm within the framework of the right to water. Reframing the facts of this case through the lens of the right to science, however, puts things in a very different perspective. The state is no longer engaged in a difficult process of progressive realization of socioeconomic rights, which courts are arguably ill-suited to second-guess. Instead, the state is more clearly seen to be actively violating the human rights of its citizens through its own reckless actions.

The implementation of a new, unproven, and potentially harmful technology calls for special ethical and legal safeguards to prevent abuse and harm. Even in jurisdictions where the right to science is not explicitly recognized, the framework of human rights safeguards as protection against problematic technologies still works. South African lawyers, for instance, might assert the right to freedom and security of 
persons, which is constitutionally defined to include the right "not to be subjected to medical or scientific experiments without their informed consent." 53 This could then be interpreted by South African courts with reference to international practice and norms related to science, such as the Belmont Report and the Universal Declaration on Bioethics and Human Rights.

Courts of law are well positioned to adjudicate human rights violations within this framework. This approach does not require courts to set minimum standards for technical performance or to reach the conclusion that a particular technology does or does not violate human rights. Instead, it asks courts to do something that is uniquely within their institutional competence: to evaluate the sufficiency of procedural safeguards. The Belmont principles offer a framework for defining the procedural rights that must be upheld when people are subjected to unproven and potentially harmful technologies, in order to prevent abuse and minimize harm. Where these procedural rights are not respected, a court might either order a technological experiment to be suspended or require specific new safeguards, such as improved consent procedures, special protections for vulnerable populations, or the freedom to opt out. A court might also order financial compensation, a formal apology, or other remedies to rectify past harm. Where the evidence demonstrates a propensity for repeated violations, a court could mandate human rights training or the creation of an ethical review board. These measures might also be stipulated by means of a settlement negotiated between the parties.

A central function of ethical scrutiny of human subjects research is to provide external oversight over potentially harmful action before it takes place. This can help to guard against conflicts of interest, where a particular researcher or agency may be insufficiently concerned with the impact on individuals involved because of their own interest in seeing the project through. Yet an equally important function of ethical review is to encourage researchers to be self-policing, in order to sensitize them to their professional duty to protect their subjects' interests and encourage them to design research protocols to minimize the potential for harm. Had the Johannesburg authorities subjected their plans for the Phiri trial of prepaid meters to an ethical evaluation of this sort, they would likely have chosen to redesign the technology, policy, and procedures, avoiding significant harm in the process.

The introduction of unproven and potentially dangerous technologies, whether formally conceptualized as research or not, should be subjected to similar safeguards. Individuals subjected to such technologies without their consent should be able to seek redress in a court of law. That court should consider whether the technology's introduction was undertaken with appropriate consideration for human rights, in the form of procedural protections such as informed consent, risk-benefit analysis, and concern for vulnerable populations. Legal accountability along these lines would focus the attention of public interest advocates, lawmakers, bureaucrats,

53 Constitution of South Africa, art. 12(2)(c). 
and corporations on the adoption of appropriate safeguards to minimize risks arising from the introduction of unproven and potentially harmful technologies. The possibility of legal liability would incentivize desirable internal caution. The same principles provide the framework for exercising that self-scrutiny within corporations and administrative agencies, as part of policy and technological design. 